\title{
Release of the Diclofenac Sodium by Nanofibers of Poly(3-hydroxybutyrate-co-3-hydroxyvalerate) Obtained from Electrospinning and Solution Blow Spinning
}

\author{
Michelle Andrade Souza, Karine Yamamura Sakamoto, \\ and Luiz Henrique Capparelli Mattoso
}

Laboratório Nacional de Nanotecnologia Para o Agronegócio (LNNA), Embrapa Instrumentação (CNPDIA), Rua XV de Novembro,
1452 Centro, 13.560-970 São Carlos, SP, Brazil

Correspondence should be addressed to Michelle Andrade Souza; souza-michelle@hotmail.com

Received 22 January 2014; Revised 28 March 2014; Accepted 11 April 2014; Published 5 May 2014

Academic Editor: Zhongkui Hong

Copyright (C) 2014 Michelle Andrade Souza et al. This is an open access article distributed under the Creative Commons Attribution License, which permits unrestricted use, distribution, and reproduction in any medium, provided the original work is properly cited.

Electrospun fibers are explored as a new system for controlled drug delivery. Novel techniques capable of obtaining polymer nanofibers have been reported in the literature. They include solution blow spinning (SBS), which is a technique to produce polymer nanofibers in the same range as electrospinning, using pressurized gas instead of high voltage. The present study investigates release characteristics of diclofenac sodium encapsulated at three concentrations $(5,10$, and $20 \% \mathrm{w} / \mathrm{v})$ in poly (3-hydroxybutyrate-co-3hydroxyvalerate) (PHBV) nanofibers made by electrospinning and SBS and determines the drug's effect on fiber morphology and structural properties. PHBV nanofibers were characterized using scanning electronic microscopy, differential scanning calorimetry, and X-ray diffraction, and the release profile was examined via UV-Vis spectrophotometry. Both electrospinning and SBS encapsulated diclofenac sodium in PHBV membranes efficiently and effectively. The profile of the in vitro release of diclofenac sodium was dependent on drug concentration and temperature. The drug reduced crystallinity and increased flexibility.

\section{Introduction}

Drug delivery control systems have received increased attention in the pharmaceutical treatment of animals as they afford several advantages compared to conventional forms of dosage, including enhanced therapeutic efficacy and low toxicity when the drug is released at a controlled rate [1]. Generally, the release time of the drug needs to be prolonged for days or several months. This can be attained by entrapping the drug within polymer structures for delivery control at reproducible rates [2]. Depending on the type of carrier used, dissolution of the pharmaceutical dose can be characterized as immediate, rapid, slow, or prolonged [1].

The majority of veterinary drug delivery systems are produced from nondegradable polymers such as silicon, polyurethane, and acetate-vinylidene copolymers. These materials, approved by government regulators, are biocompatible, inert, and expensive. Interest in biodegradable polymers as delivery control systems for veterinary applications has increased as they do not require removal following treatment. These biodegradable systems suffer degradation and can be rapidly expelled by the body. They can provide significant benefits such as reductions in cost and stress on the animal. At present, however, few biodegradable drug delivery systems are commercially viable for veterinary use as factors such as product cost, regulatory burdens, and the instability of some formulations have limited their development [2].

It is important to know if the drug delivery system is intended for the treatment of domestic animals or livestock, the principal applications of veterinary medicine. Biodegradable systems of drug delivery for veterinary use as microspheres and implants, including in situ, have been tested for temperature control, growth, ectoparasitic control, vaccine and antibiotics delivery, and use as antiparasitic agents and steroids for fertility control $[2,3]$.

Electrospun nanofibers have been developed from several synthetic materials such as copolymers, natural polymers, and blends, including proteins. The use of copolymers is 


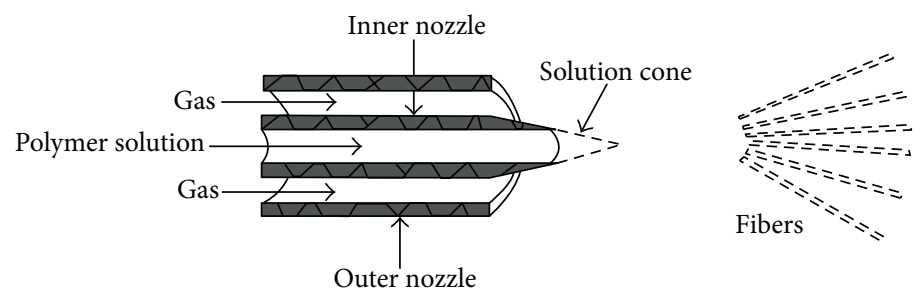

(a)

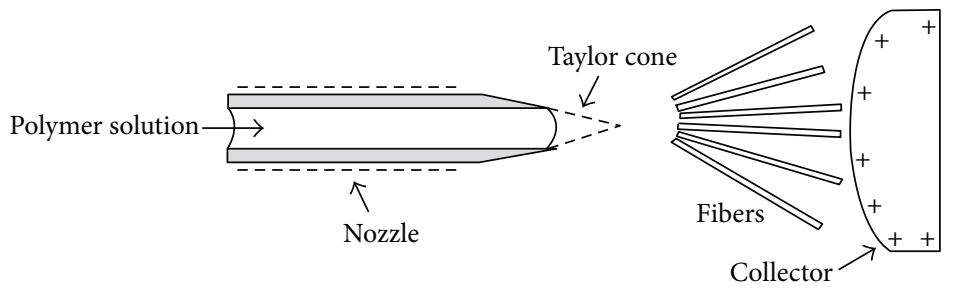

(b)

FIGURE 1: Cutaway diagram of the concentric nozzle system used in solution blow spinning (a) and electrospinning (b) [20].

a viable means to generate new materials with desired properties, which can constitute an improvement in comparison to those of homopolymers [4]. As a result of its low thermal stability, rigidity, and low stress resistance, $\mathrm{PHB}$ polymer is not commonly used in industrial applications. The introduction of 3-hydroxyvaleric acids to PHB forms the PHBV copolymer, which is more flexible, malleable, and less crystalline; it enables a lower melting point and greater processability than $\mathrm{PHB}[5,6]$. This copolymer can be used to prepare films with excellent physical, mechanical, and chemical properties, which can be processed at low temperatures.

Electrospun fibers have been explored as a system for drug delivery control [1]. Nanofibers have been used as drug delivery systems because of their functional characteristics, capacity to deliver drugs in specific targets, and improved dissolution rates in particular drugs through increased surface area [2]. Another advantage of nanofibers is their ability to encapsulate diverse drugs. In view of their high surface energy and porous structures, electrospun nanofibers are used in many fields such as medicine, veterinary medicine, biosensors, solar cells, tissue engineering, nanocomposites, catalysts, and antimicrobial materials and membranes [1].

PHBV has replaced the use of plastics derived from petroleum in various applications such as food packaging. PHBV is also used in drug delivery systems in medicine, veterinary medicine, and agriculture [5,7]. Anti-inflammatories are drugs that have the capacity to control inflammation, act as analgesics, and prevent fever [8]. Diclofenac sodium is recommended for human and animal use in cases of pain, fever, and inflammation $[9,10]$.

The majority of commercial microfibers and nanofibers are produced by melt spinning [11], solution spinning [12], and melt blowing $[13,14]$, while nanofibers are produced by electrospinning [15-17] and solution blow spinning (SBS) [18-22] on a noncommercial scale. Electrospinning process is an electrohydrodynamic phenomenon capable of producing fibers with diameters ranging from micrometers to nanometers [17]. The development of new techniques capable of obtaining polymer nanofibers has been reported [18]. Methods such as solution blow spinning seek to exceed the productivity of electrospinning. SBS uses a matrix comprised of concentric channels with optimized geometry that enables the production of polymer nanofibers. Whereas electrospinning uses high voltage, SBS uses pressurized gas. The latter technique provides such advantages as high productivity, low operational cost, and the absence of an electric field and is 100 times faster than electrospinning [18-22]; see Figure 1.

The present study investigates the release characteristics of diclofenac sodium encapsulated in poly(3-hydroxybutyrate-co-3-hydroxyvalerate) nanostructured membranes by electrospinning and SBS and considers the effect of this encapsulation on the morphology and structural properties of PHBV nanofibers.

\section{Materials and Methods}

2.1. Materials. Poly(3-hydroxybutyrate-co-3-hydroxyvalerate) (PHBV) was obtained from Natureworks (São Paulo, Brazil). Diclofenac sodium and hexafluoroisopropanol were purchased from Sigma-Aldrich. Hexafluoroisopropanol was used as solvent to prepare the polymeric solutions. The chemical structures of polymer and drug are illustrated in Figure 2.

2.2. Preparation of Solutions. To prepare solutions, amounts of PHBV were weighed and dissolved in hexafluoroisopropanol $(8 \% \mathrm{wt})$ under vigorous stirring for several hours until complete dissolution was attained. Diclofenac sodium was also weighed and added to PHBV solutions at different ratios $(5,10$, and $20 \% \mathrm{w} / \mathrm{w})$ to study its controlled release. 


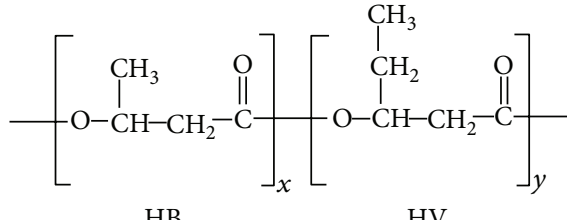

(a)

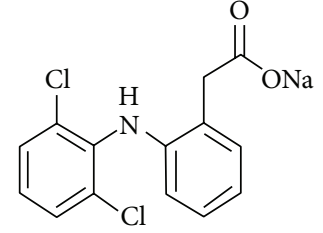

(b)

FIGURE 2: Chemical structures: poly(3-hydroxybutyrate-co-3-hydroxyvalerate) (PHBV) (a) and diclofenac sodium (b).

TABLE 1: Fiber diameters.

\begin{tabular}{lcccc}
\hline & \multicolumn{2}{c}{ Mean diameters (nm) } \\
Samples & Neat PHBV & PHBV $+5 \%$ diclofenac & PHBV + 10\% diclofenac & PHBV + 20\% diclofenac \\
\hline Electrospun fibers & $246 \pm 1.5$ & $450.1 \pm 40.5$ & $480 \pm 54$ & $577.4 \pm 25.7$ \\
SBS spun fibers & $263 \pm 4.4$ & $317.4 \pm 2.2$ & $320.4 \pm 3$ & $276.6 \pm 5.8$ \\
\hline
\end{tabular}

2.3. Fiber Spinning. Fibers were prepared by solution blow spinning at an air pressure of $0.4 \mathrm{MPa}$, a distance of $12 \mathrm{~cm}$, and rate of $7.2 \mu \mathrm{L} \cdot \mathrm{min}^{-1}$. An SBS apparatus comprised of two concentric nozzles, whose protruding inner nozzle had a diameter of 0.5 and a length of $2 \mathrm{~mm}$, was used. Fibers prepared by electrospinning were spun at a distance of $12 \mathrm{~cm}$ and rate of $0.4 \mathrm{~mL} \cdot \mathrm{h}^{-1}$ using a voltage of $25 \mathrm{kV}$.

2.4. Characterization of Spun Fibers. Fiber morphology was observed using a model JSM-6510/GS scanning electron microscope (JEOL, Germany) after gold-coating with a SCD 050 sputtering system (OerlikonBalzers, Liechtenstein). Fiber diameter was measured with the aid of image software (Image J, National Institutes of Health, USA) for some 100 random measurements using micrographs representative of fiber morphology.

For characterization by X-ray diffraction (XRD), pieces of fiber were collected from webs on aluminum foil and wrapped around circular glass slides. X-ray diffraction patterns were recorded using a XRD-6000 diffractometer (Shimadzu, Japan). Scans were made in a $2 \theta$ scale from $10^{\circ}$ to $30^{\circ}$ at a rate of $2^{\circ} / \mathrm{min}$ using $\mathrm{Ni}$-filtered $\mathrm{CuK} \alpha$ radiation. The width of the diffraction peaks at half-maximum height was calculated by applying a Gaussian-Lorentzian function (Microcal Origin, USA) to the XRD data. The $d$-spacing for a given scattering angle, $2 \theta$, was calculated by applying the Bragg equation:

$$
d=\frac{\lambda}{2 \cdot \sin \theta}
$$

where $\lambda$ is the wavelength of the $\operatorname{CuK} \alpha$ radiation $(\lambda=$ $0.154 \mathrm{~nm}$ ). The width of the diffraction peaks at halfmaximum height was calculated by applying a Lorentzian function to the XRD data, and the crystallite size, $D$, was estimated by calculating the width of the diffraction peaks according to the Scherrer equation:

$$
D=\frac{K \cdot \lambda}{\beta \cdot \cos \theta},
$$

where $K$ is a constant that depends upon lattice direction and crystallite morphology and $\beta$ is the full width at halfmaximum height given in radians. The study used $K$ value of 0.9 , based on values found in the literature for these polymers.

Differential scanning calorimetry studies were performed using a model Q100 calorimeter (TA Instruments, USA) under nitrogen atmosphere at a flow rate of $80 \mathrm{~mL} / \mathrm{min}$. Each sample was first heated from $0^{\circ} \mathrm{C}$ to $180^{\circ} \mathrm{C}$ at $10^{\circ} \mathrm{C} / \mathrm{min}$, held for $2 \mathrm{~min}$, cooled to $0^{\circ} \mathrm{C}$ at $10^{\circ} \mathrm{C} / \mathrm{min}$, and finally reheated to $180^{\circ} \mathrm{C}$ at $10^{\circ} \mathrm{C} / \mathrm{min}$.

2.5. In Vitro Drug Release. The amount of diclofenac sodium released was monitored at $\lambda=280 \mathrm{~nm}$ using the following process: $50 \mathrm{mg}$ of spun mat or film was placed in a $50 \mathrm{~mL}$ phosphate buffer of $\mathrm{pH} 7.4$ and shaken in a water bath at room temperature $\left(20^{\circ} \mathrm{C}\right)$ and normal body temperature $\left(37^{\circ} \mathrm{C}\right)$; then $3 \mathrm{~mL}$ was collected for analysis and returned to the release medium. The cumulative amount of diclofenac sodium released over time was calculated.

\section{Results and Discussion}

3.1. Scanning Electronic Microscopy. Figure 3 shows the morphology of the PHBV nanofibers obtained by electrospinning at different concentrations of diclofenac sodium.

The PHBV polymer containing diclofenac sodium at different concentrations (5, 10, and 20\%) demonstrated morphology predominantly composed of nanofibers with diameters of approximately $500 \mathrm{~nm}$. This demonstrates the formation of PHBV nanofibers by electrospinning.

Figure 4 shows the morphology of PHBV nanofibers obtained by solution blow spinning at different concentrations of diclofenac sodium.

The PHBV polymer containing diclofenac sodium at different concentrations revealed morphology predominantly composed of nanofibers with approximately $500 \mathrm{~nm}$ diameters. This demonstrates the formation of PHBV nanofibers by solution blow spinning. Table 1 exhibits the average diameters of PHBV nanofibers produced by each process. 


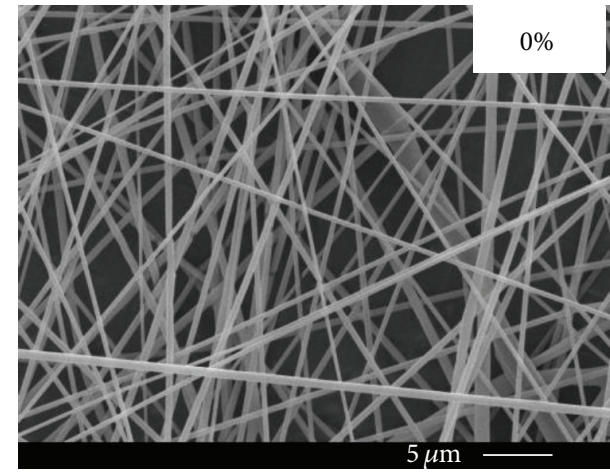

(a)

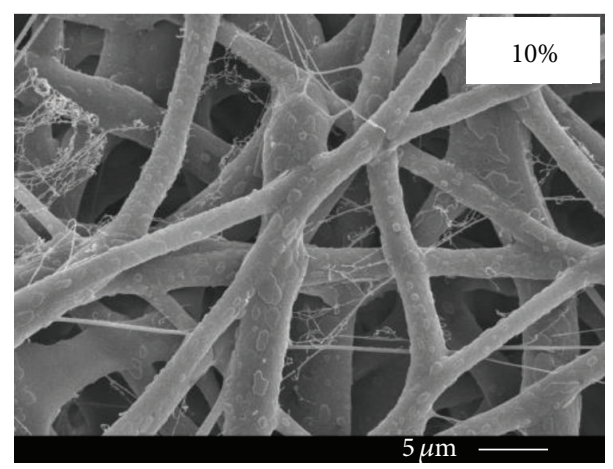

(c)

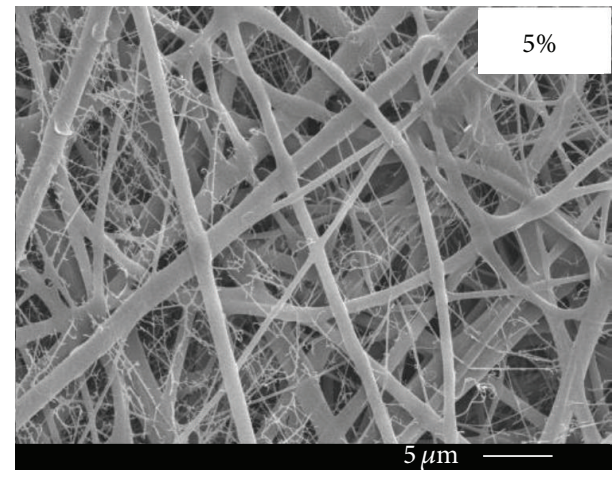

(b)

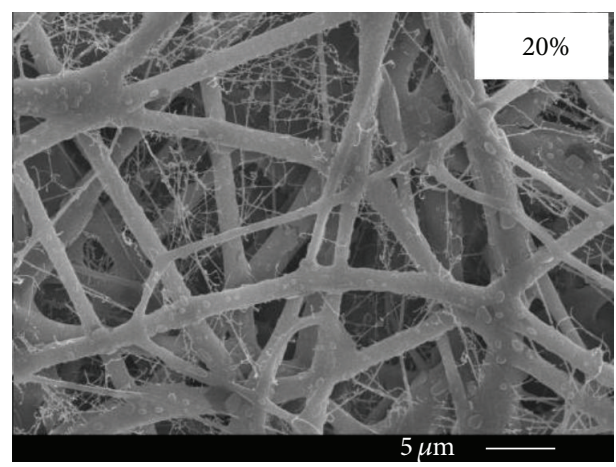

(d)

FIGURE 3: PHBV nanofibers at different concentrations of diclofenac sodium (electrospinning).

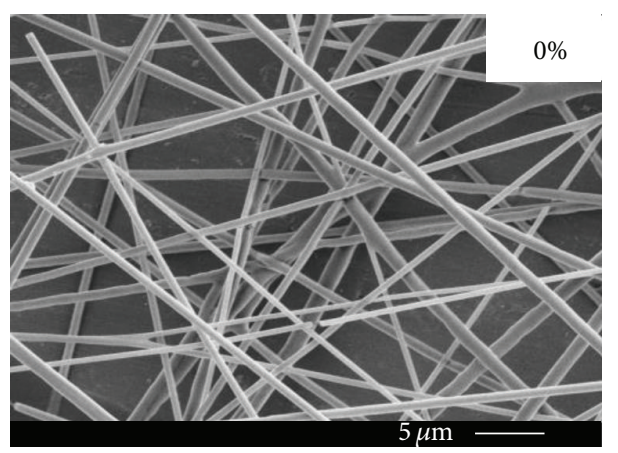

(a)

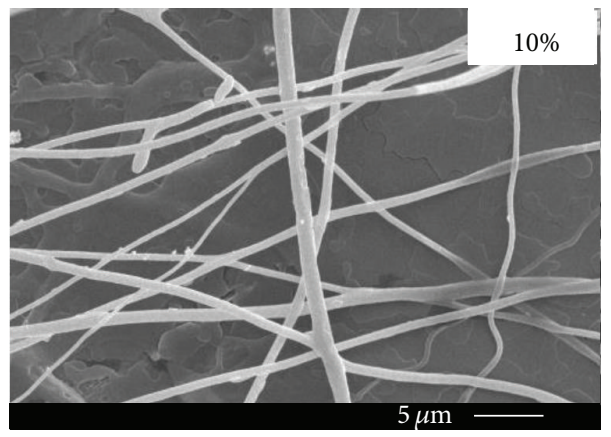

(c)

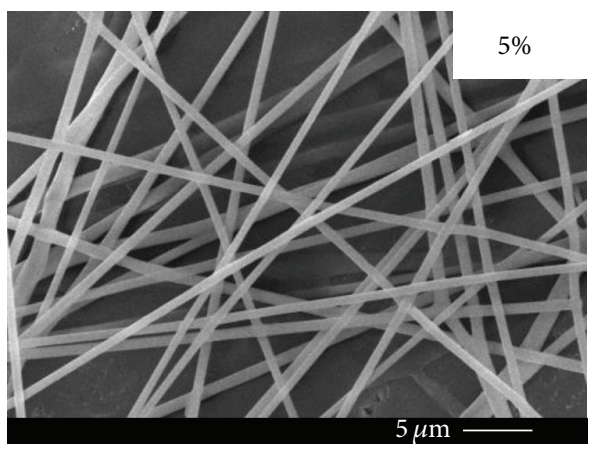

(b)

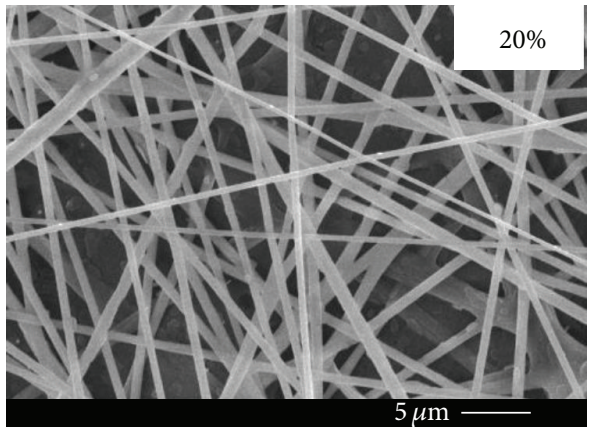

(d)

FIGURE 4: PHBV nanofibers at different concentrations of diclofenac sodium (SBS). 
TABLE 2: Thermal properties of PHBV nanofibers produced by electrospinning (ES) and solution blow spinning (SBS).

\begin{tabular}{|c|c|c|c|c|c|c|}
\hline Samples & Techniques & $T_{m}\left({ }^{\circ} \mathrm{C}\right)$ & $\Delta H_{m}(\mathrm{~J} / \mathrm{g})$ & $T_{c}\left({ }^{\circ} \mathrm{C}\right)$ & $\Delta H_{c}(\mathrm{~J} / \mathrm{g})$ & $X_{c}(\%)$ \\
\hline \multirow{2}{*}{ Neat PHBV } & ES & $164.3 \pm 3.5$ & $44.3 \pm 26.4$ & - & - & - \\
\hline & SBS & $168.5 \pm 1.2$ & $11.8 \pm 1.5$ & - & - & - \\
\hline \multirow{2}{*}{ PHBV + 5\% Diclof. } & ES & $147.5 \pm 5.2 / 132.3 \pm 2.8$ & $55.7 \pm 5 / 7.8 \pm 4.8$ & $37.5 \pm 2.1$ & $10 \pm 5.6$ & $38.8 \pm 9.5$ \\
\hline & SBS & $135 \pm 7 / 134.7 \pm 11.4$ & $63.6 \pm 2.4 / 3.4 \pm 0.01$ & $48.1 \pm 3$ & $36.1 \pm 4.5$ & $26 \pm 8.1$ \\
\hline \multirow{2}{*}{ PHBV + 10\% Diclof. } & ES & $136.6 \pm 0.7 / 137.1 \pm 1.2$ & $61.7 \pm 6.3 / 2.7 \pm 0.5$ & 40.1 & 26.5 & 28.1 \\
\hline & SBS & $142.4 \pm 3.4 / 125.6 \pm 2.3$ & $63.6 \pm 2.4 / 3.4 \pm 0.01$ & $46.6 \pm 1.4$ & $35.8 \pm 4.7$ & $25.5 \pm 2.1$ \\
\hline \multirow{2}{*}{ PHBV + 20\% Diclof. } & ES & $138 \pm 1.8 / 126.6 \pm 2$ & $46 \pm 1.3 / 4.3 \pm 0.2$ & - & - & - \\
\hline & SBS & $141.1 \pm 2 / 129 \pm 3.3$ & $56.1 \pm 17 / 6.1 \pm 2$ & - & - & - \\
\hline
\end{tabular}

$T_{m}$ : melting temperature; $\Delta H_{m}$ : fusion enthalpy; $T_{c}$ : crystallization temperature; $\Delta H_{c}$ : crystallization enthalpy; $X_{c}$ : crystallization degree.

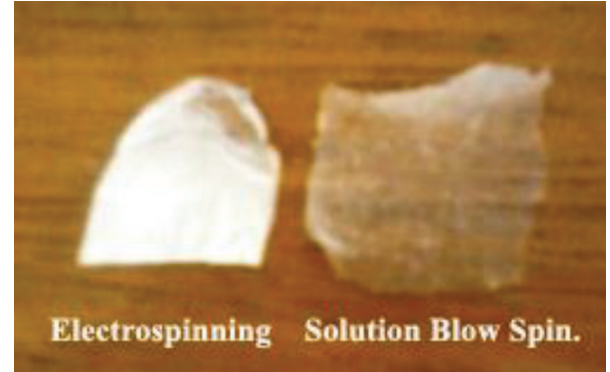

FIGURE 5: Visual aspect of PHBV nanofibers produced by electrospinning and SBS.

Note that the average diameters of PHBV nanofibers produced by solution blow spinning are smaller than those produced by electrospinning. This fact can be related to forces involved in the fiber formation in each process. During fiber formation by SBS, a jet of polymer solution is subjected to aerodynamic drag. As this jet travels through the air, the solvent evaporates, leaving behind ultrafine polymer fibers. The shear forces that act upon the polymer solutions are therefore responsible for fiber stretching and, ultimately, for fiber diameter distribution. In contrast, fiber formation in electrospinning is controlled by electrostatic repulsive forces that overcame surface tension, while a charged jet is ejected through a needle to produce fibers. Stretching by electric forces taking place on the surface of the jet is an important step during fibers formation. Therefore, in electrospinning, fiber formation is more dependent on surface tension [20].

PHBV nanofibers produced by SBS exhibit a transparent visual aspect, while PHBV nanofibers produced by electrospinning are opaque; see Figure 5.

This distinction could be related to chain orientation, which differs in each process. According to Oliveira et al., an additional factor that may contribute to this difference could be the time expended [20]. Solution blow spinning is approximately 10 times faster than electrospinning and yields a greater amount of polymer. The higher speed and characteristic forces of SBS likely favor chain orientation that leads to a higher crystallinity than electrospinning. Accordingly, nanofibers produced by electrospinning and SBS can be suitable for different applications as a result of their distinct optical properties.
3.2. Differential Scanning Calorimetry. Table 2 details the thermal behavior of the PHBV nanofibers containing diclofenac sodium produced by electrospinning and solution blow spinning.

As can be seen in Table 2, $T_{m}$ values are reduced with the addition of diclofenac sodium at different concentrations using electrospinning and SBS. This demonstrates that the drug can act as a plasticizer, increasing the flexibility of PHBV nanofibers. Plasticizers are an important class of nonvolatile compounds of low molecular weight used as additives in the thermoplastic industry. Their principal function is to improve the flexibility and processability of polymers, for example, by reducing vitreous transition temperature $\left(T_{g}\right)$ $[23,24]$. The addition of plasticizers also increases the flexibility of films as a result of their presence between polymer chains, which reduces intermolecular interactions through chain separation, thus promoting mobility [24]. These additives reduce the tension of deformation, hardness, density, viscosity, and electrostatic load, while increasing the flexibility of the polymer chain, fracture resistance, and the dielectric constant $[25,26]$. Other properties affected include crystallinity, optical characteristics, electric conductivity, and biologic degradation resistance $[27,28]$. Since the nanofibers' properties attained by solution blow spinning are analogous to those obtained from electrospinning, it is evident that SBS is an efficient and effective drug delivery system.

3.3. X-Ray Diffraction. Figure 6 shows the X-ray diffraction pattern of PHBV nanofibers encapsulating diclofenac sodium obtained by electrospinning (ES) and solution blow spinning (SBS).

In all cases, the two peaks at about $2 \theta=13.4^{\circ}$ and $16^{\circ}$ have to be associated to the PHBV component, corresponding, respectively, to the (020) and (110) reflections of the orthorhombic unit cell [29-31].

It can be observed that all samples exhibit peaks in the same region. So, modification was not observed in the crystalline structure of the polymer. These XRD results indicate that crystalline structure of the polymer was not affected by addition of diclofenac sodium at different concentrations too in both processes (ES and SBS).

Tables 3 and 4 detail the interplanar distances and crystal diameters of these PHBV nanofibers, respectively. 
Electrospinning

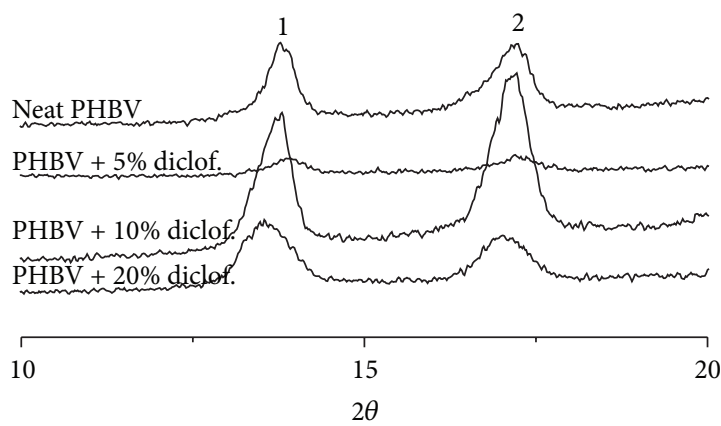

(a)

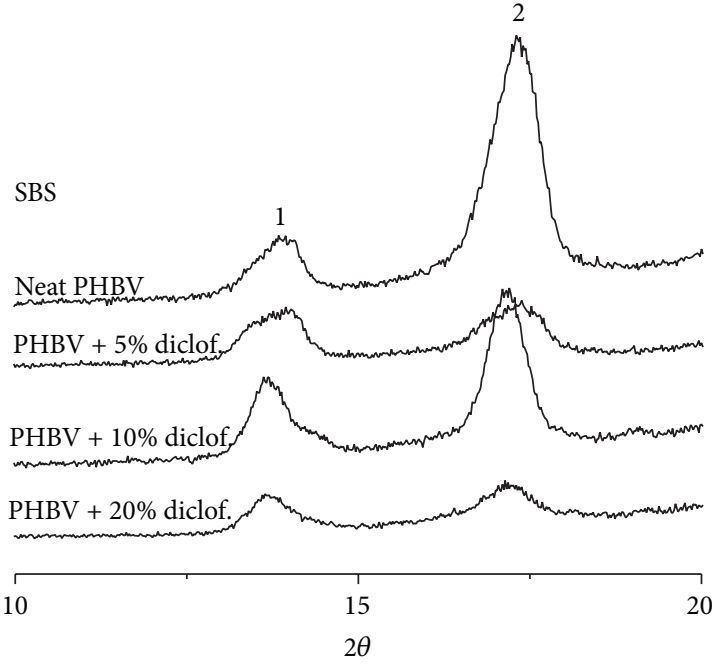

(b)

FIgURE 6: PHBV nanofibers at different concentrations of diclofenac sodium produced by electrospinning (a) and SBS (b).

TABLE 3: Interplanar distances $(d)$ as to crystalline parts of PHBV nanofibers obtained by electrospinning (ES) and solution blow spinning (SBS).

\begin{tabular}{lccc}
\hline Samples & Tech. & $d_{1}(\AA)$ & $d_{2}(\AA)$ \\
\hline \multirow{2}{*}{ Neat PHBV } & ES & $4.7 \pm 2.4$ & $4.1 \pm 1.4$ \\
& SBS & $4.6 \pm 2.3$ & $4.1 \pm 1.4$ \\
\hline \multirow{2}{*}{ PHBV + 5\% Diclof. } & ES & $4.7 \pm 2.4$ & $4.2 \pm 1.5$ \\
& SBS & $4.7 \pm 2.4$ & $4.1 \pm 1.4$ \\
\hline \multirow{2}{*}{ PHBV + 10\% Diclof. } & ES & $4.7 \pm 2.4$ & $4.2 \pm 1.5$ \\
& SBS & $4.7 \pm 2.4$ & $4.2 \pm 1.5$ \\
\hline \multirow{2}{*}{ PHBV + 20\% Diclof. } & ES & $4.7 \pm 2.5$ & $4.2 \pm 1.5$ \\
& SBS & $4.5 \pm 2.8$ & $4.3 \pm 1.2$ \\
\hline
\end{tabular}

TABLE 4: Crystallite diameters $(D)$ of PHBV nanofibers obtained by electrospinning (ES) and solution blow spinning (SBS).

\begin{tabular}{lccc}
\hline Samples & Tech. & $D_{1}(\AA)$ & $D_{2}(\AA)$ \\
\hline \multirow{2}{*}{ Neat PHBV } & ES & $8.8 \pm 8.9$ & $6.7 \pm 6.9$ \\
& SBS & $5.3 \pm 6.8$ & $6.2 \pm 5$ \\
\hline \multirow{2}{*}{ PHBV + 5\% Diclof. } & ES & $6 \pm 4.1$ & $5.6 \pm 4.5$ \\
& SBS & $7.9 \pm 6.7$ & $7.4 \pm 7.2$ \\
\hline \multirow{2}{*}{ PHBV + 10\% Diclof. } & ES & $8.1 \pm 5.7$ & $6.6 \pm 5.2$ \\
& SBS & $6.4 \pm 5.5$ & $6.2 \pm 6.5$ \\
\hline \multirow{2}{*}{ PHBV + 20\% Diclof. } & ES & $7.1 \pm 5.4$ & $6.1 \pm 5.2$ \\
& SBS & $8.5 \pm 7.4$ & $0.8 \pm 1.1$ \\
\hline
\end{tabular}

The interplanar distances are not affected by the presence of diclofenac sodium in either technique. As the crystal diameters vary, however, it is likely that there was insufficient time to form perfect crystal as a result of their rapid solidification. Diclofenac sodium is probably acting on and within the crystals.
TABLE 5: Cumulative diclofenac sodium released.

\begin{tabular}{lccccc}
\hline \multicolumn{5}{c}{ Cumulative diclofenac sodium released } \\
Time & & $2 \mathrm{~h}$ (initial) & \multicolumn{2}{c}{$12 \mathrm{~h}$ (final) } \\
Temperature & & $20^{\circ} \mathrm{C}$ & $37^{\circ} \mathrm{C}$ & $20^{\circ} \mathrm{C}$ & $37^{\circ} \mathrm{C}$ \\
\hline \multirow{2}{*}{ PHBV + 5\% Diclof. } & ES & $39.2 \%$ & $48.2 \%$ & $61.8 \%$ & $75 \%$ \\
& SBS & $4.7 \%$ & $7.7 \%$ & $22.4 \%$ & $60.6 \%$ \\
\hline \multirow{2}{*}{ PHBV + 10\% Diclof. } & Es & $54.8 \%$ & $60.5 \%$ & $63.4 \%$ & $81.7 \%$ \\
& SBS & $24.4 \%$ & $58.4 \%$ & $61.3 \%$ & $85.5 \%$ \\
\hline \multirow{2}{*}{ PHBV + 20\% Diclof. } & ES & $78.9 \%$ & $78 \%$ & $85.6 \%$ & $87.5 \%$ \\
& SBS & $49.6 \%$ & $71.6 \%$ & $100 \%$ & $100 \%$ \\
\hline
\end{tabular}

3.4. In Vitro Drug Release. Figure 7 demonstrates the release profile of PHBV nanofibers containing diclofenac sodium at two different temperatures, namely, $20^{\circ}$ and $37^{\circ} \mathrm{C}$.

Table 5 exhibits the rates of diclofenac sodium released at different concentrations and temperatures.

In each process, the release rate of diclofenac sodium is higher at $37^{\circ} \mathrm{C}$ than at $20^{\circ} \mathrm{C}$. This phenomenon is anticipated as the release rate from the PHBV membrane is diffusion dependent, and the diffusion rate increases with a rise in temperature [32-34]. Moreover, anti-inflammatory drug delivery depends on drug concentration in the nanofibers in which increasing amounts of drugs gave rise to higher release rates.

\section{Conclusion}

An innovative system of drug delivery from PHBV nanofibers' membranes produced by slow blow spinning was compared with electrospinning. Both processes proved efficient and effective in encapsulating diclofenac sodium in nanofiber membranes. Diclofenac sodium impacts physical properties (crystallinity, interplanar distance, and crystals diameters) and improves flexibility. These properties are 


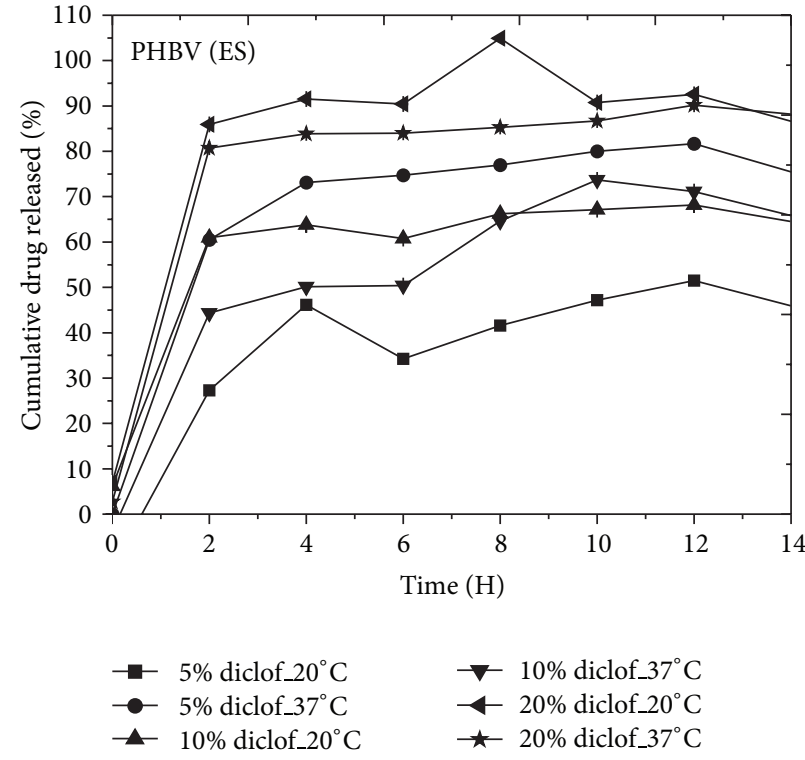

(a)

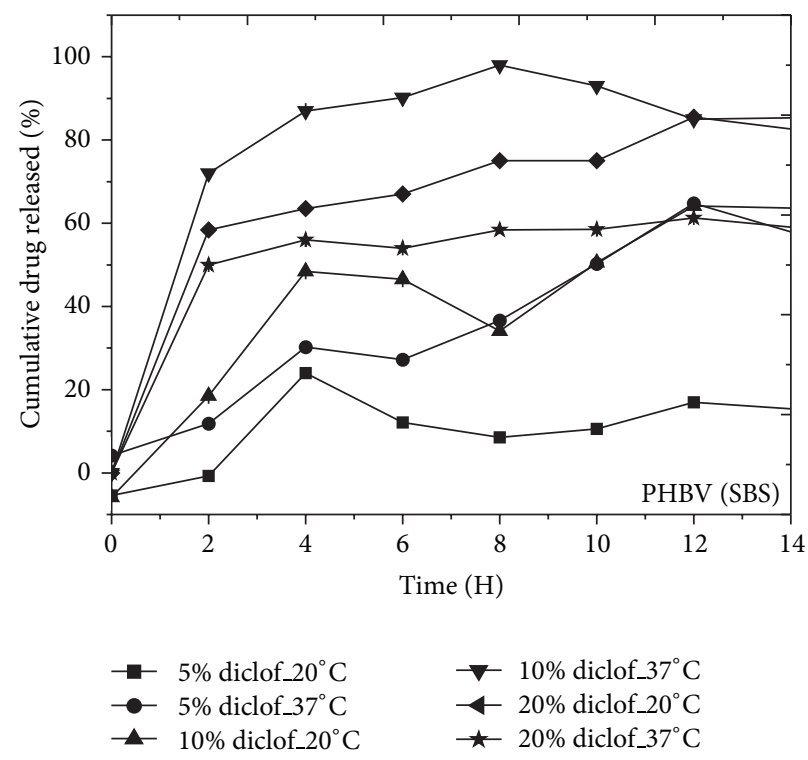

(b)

FIGURE 7: In vitro release of diclofenac sodium, produced by electrospinning (ES) (a) and slow blow spinning (SBS) (b) from PHBV nanofibers at $20^{\circ}$ and $37^{\circ} \mathrm{C}$.

analogous for PHBV nanofibers produced by either process. The in vitro release of diclofenac sodium depends on temperature and drug concentration in the nanofibers. The development of PHBV membranes encapsulating diclofenac sodium could be useful in creating new commercial markets with potential applications in controlled-release devices in human and veterinary medicine.

\section{Conflict of Interests}

The authors declare that there is no conflict of interests regarding the publication of this paper.

\section{Acknowledgments}

The authors express their gratitude to the Conselho Nacional de Pesquisa e Desenvolvimento (CNPq. 163161/2011-9, CNPq. 307935/2004-3, CNPq. 562470/2010-7, and CNPq. 56485/2010-8), Fundação de Apoio a Pesquisa do Estado de São Paulo (FAPESP, 02010/19860-1), and Coordenação de Aperfeiçoamento de Pessoal de nível Superior (CAPES) for their funding and support of this research.

\section{References}

[1] E.-R. Kenawy, F. I. Abdel-Hay, M. H. El-Newehy, and G. E. Wnek, "Processing of polymer nanofibers through electrospinning as drug delivery systems," Materials Chemistry and Physics, vol. 113, no. 1, pp. 296-302, 2009.

[2] G. Winzenburg, C. Schmidt, S. Fuchs, and T. Kissel, "Biodegradable polymers and their potential use in parenteral veterinary drug delivery systems," Advanced Drug Delivery Reviews, vol. 56, no. 10, pp. 1453-1466, 2004.
[3] D. H. Carter, M. Luttinger, and D. L. Gardner, "Controlled release parenteral systems for veterinary applications," Journal of Controlled Release, vol. 8, no. 1, pp. 15-22, 1988.

[4] D. Liang, B. S. Hsiao, and B. Chu, "Functional electrospun nanofibrous scaffolds for biomedical applications," Advanced Drug Delivery Reviews, vol. 59, no. 14, pp. 1392-1412, 2007.

[5] C. A. Carminatti, Copolímeros de 3-hidroxibutirato-co-3-hidroxivalerato $(\mathrm{PHBV})$ produzidos por chromobacterium violaceum [Tese de Doutorado], Departamento de Engenharia Química, Universidade Federal de Santa Catarina, Florianópolis, Florianópolis, Brazil, 2008.

[6] M. Sokolsky-Papkov, K. Agashi, A. Olaye, K. Shakesheff, and A. J. Domb, "Polymer carriers for drug delivery in tissue engineering," Advanced Drug Delivery Reviews, vol. 59, no. 4-5, pp. 187-206, 2007.

[7] L. C. A. Silva, Obtenção e caracterização de nanocompósitos à base de Polihidroxialcanoato/Atapulgita [Dissertação de Mestrado], Departamento de Ciência e Engenharia de Materiais, Universidade Federal de Sergipe, São Cristóvão, Brazil, 2008.

[8] http://wwwbayersaudeanimal.com.br/html/pdf/bula/bovinos/ FLUNAMINE_BULA.pdf, 2012.

[9] M. Ferrante, A. Andreeta, and M. F. Landoni, "Effect of different penetration enhancers on diclofenac permeation across horse skin," Veterinary Journal, vol. 186, no. 3, pp. 312-315, 2010.

[10] http://www.sigma-aldrich.com/, 2012.

[11] S. Kase and T. Matsuo, "Studies on melt spinning. I. Fundamental equations on the dynamics of melt spinning," Journal of Polymer Science Part A-General Papers, vol. 3, pp. 2541-2554, 1965.

[12] P. Smith and P. J. Lemstra, "Ultra-high-strength polyethylene filaments by solution spinning/drawing," Journal of Materials Science, vol. 15, no. 2, pp. 505-514, 1980. 
[13] S. Sinha-Ray, A. L. Yarin, and B. Pourdeyhimi, "Meltblowing: I-basic physical mechanisms and threadline model," Journal of Applied Physics, vol. 108, no. 3, Article ID 034912, 2010.

[14] D. H. Tan, C. Zhou, C. J. Ellison, S. Kumar, C. W. Macosko, and F. S. Bates, "Meltblown fibers: influence of viscosity and elasticity on diameter distribution," Journal of Non-Newtonian Fluid Mechanics, vol. 165, no. 15-16, pp. 892-900, 2010.

[15] D. Li and Y. Xia, "Electrospinning of nanofibers: reinventing the wheel?” Advanced Materials, vol. 16, no. 14, pp. 1151-1170, 2004.

[16] S. Ramakrishna, K. Fujihara, W.-E. Teo, T. Yong, Z. Ma, and R. Ramaseshan, "Electrospun nanofibers: solving global issues," Materials Today, vol. 9, no. 3, pp. 40-50, 2006.

[17] D. H. Reneker and I. Chun, "Nanometre diameter fibres of polymer, produced by electrospinning," Nanotechnology, vol. 7, no. 3, pp. 216-223, 1996.

[18] E. S. Medeiros, G. M. Glenn, A. P. Klamczynski, W. J. Orts, and L. H. C. Mattoso, "Solution blow spinning: a new method to produce micro- and nanofibers from polymer solutions," Journal of Applied Polymer Science, vol. 113, no. 4, pp. 2322-2330, 2009.

[19] J. E. Oliveira, E. S. Medeiros, L. Cardozo et al., "Development of poly (lactic acid) nanostructured membranes for the controlled delivery of progesterone to livestock animals," Materials Science and Engineering C, vol. 33, p. 844, 2013.

[20] J. E. Oliveira, E. S. Medeiros, L. H. C. Mattoso, and W. J. Orts, "Structural and morphological characterization of micro and nanofibers produced by electrospinning and solution blow spinning: A Comparative Study," Advances in Materials Science and Engineering, vol. 2013, Article ID 409572, 14 pages, 2013.

[21] J. E. Oliveira, E. A. Moraes, J. M. Marconcini, L. H. C. Mattoso, G. M. Glenn, and E. S. Medeiros, "Properties of poly (lactic acid) and poly (ethylene oxide) solvent polymer mixtures and nanofibers made by solution blow spinning," Journal of Applied Polymer Science, vol. 129, no. 6, pp. 3672-3681, 2013.

[22] J. E. Oliveira, E. A. Moraes, R. G. F. Costa et al., "Nano and submicrometric fibers of poly(D, L -lactide) obtained by solution blow spinning: process and solution variables," Journal of Applied Polymer Science, vol. 122, no. 5, pp. 3396-3405, 2011.

[23] H. C. Erythropel, M. Maric, and D. G. Cooper, "Designing green plasticizers: influence of molecular geometry on biodegradation and plasticization properties," Chemosphere, vol. 86, no. 8, pp. 759-766, 2012.

[24] R. P. H. Brandelero, F. Yamashita, and M. V. E. Grossmann, "The effect of surfactant Tween 80 on the hydrophilicity, water vapor permeation, and the mechanical properties of cassava starch and poly(butylene adipate-co-terephthalate) (PBAT) blend films," Carbohydrate Polymers, vol. 82, no. 4, pp. 1102-1109, 2010.

[25] V. S. Silverajah, N. A. Ibrahim, N. Zainuddin, W. M. Yunus, and H. A. Hassan, "Mechanical, thermal and morphological properties of poly(lactic acid)/epoxidized palm olein blend," Molecules, vol. 17, no. 10, pp. 11729-11747, 2012.

[26] E. R. Jusoh, M. Halim Shah Ismail, L. C. Abdullah, Y. Robiah, and W. A. Wan Abdul Rahman, "Crude palm oil as a bioadditive in polypropylene blown films," BioResources, vol. 7, no. 1, pp. 859-867, 2012.

[27] R. J. Jaeger and R. J. Rubin, "Migration of a phthalate ester plasticizer from polyvinyl chloride blood bags into stored human blood and its localization in human tissues," The New England Journal of Medicine, vol. 287, no. 22, pp. 1114-1118, 1972.
[28] S. Loff, F. Kabs, K. Witt et al., "Polyvinylchloride infusion lines expose infants to large amounts of toxic plasticizers," Journal of Pediatric Surgery, vol. 35, no. 12, pp. 1775-1781, 2000.

[29] C. Del Gaudio, E. Ercolani, F. Nanni, and A. Bianco, "Assessment of poly(eopen-caprolactone)/poly(3-hydroxybutyrate-co3-hydroxyvalerate) blends processed by solvent casting and electrospinning," Materials Science and Engineering A, vol. 528, no. 3, pp. 1764-1772, 2011.

[30] W. Yu, C.-H. Lan, S.-J. Wang, P.-F. Fang, and Y.-M. Sun, "Influence of zinc oxide nanoparticles on the crystallization behavior of electrospun poly(3-hydroxybutyrate-co-3-hydroxyvalerate) nanofibers," Polymer, vol. 51, no. 11, pp. 2403-2409, 2010.

[31] M.-L. Cheng, C.-C. Lin, H.-L. Su, P.-Y. Chen, and Y.-M. Sun, "Processing and characterization of electrospun poly(3hydroxybutyrate-co-3-hydroxyhexanoate) nanofibrous membranes," Polymer, vol. 49, no. 2, pp. 546-553, 2008.

[32] E.-R. Kenawy, F. I. Abdel-Hay, M. H. El-Newehy, and G. E. Wnek, "Controlled release of ketoprofen from electrospun poly(vinyl alcohol) nanofibers," Materials Science and Engineering A, vol. 459, no. 1-2, pp. 390-396, 2007.

[33] E.-R. Kenawy, F. Abdel-Hay, M. El-Newehy, and R. M. Ottenbrite, "Effect of $\mathrm{pH}$ on the drug release rate from a new polymer-drug conjugate system," Polymer International, vol. 57, no. 1, pp. 85-91, 2008.

[34] E.-R. Kenawy, F. I. Abdel-Hay, M. H. El-Newehy, and G. E. Wnek, "Processing of polymer nanofibers through electrospinning as drug delivery systems," Materials Chemistry and Physics, vol. 113, no. 1, pp. 296-302, 2009. 

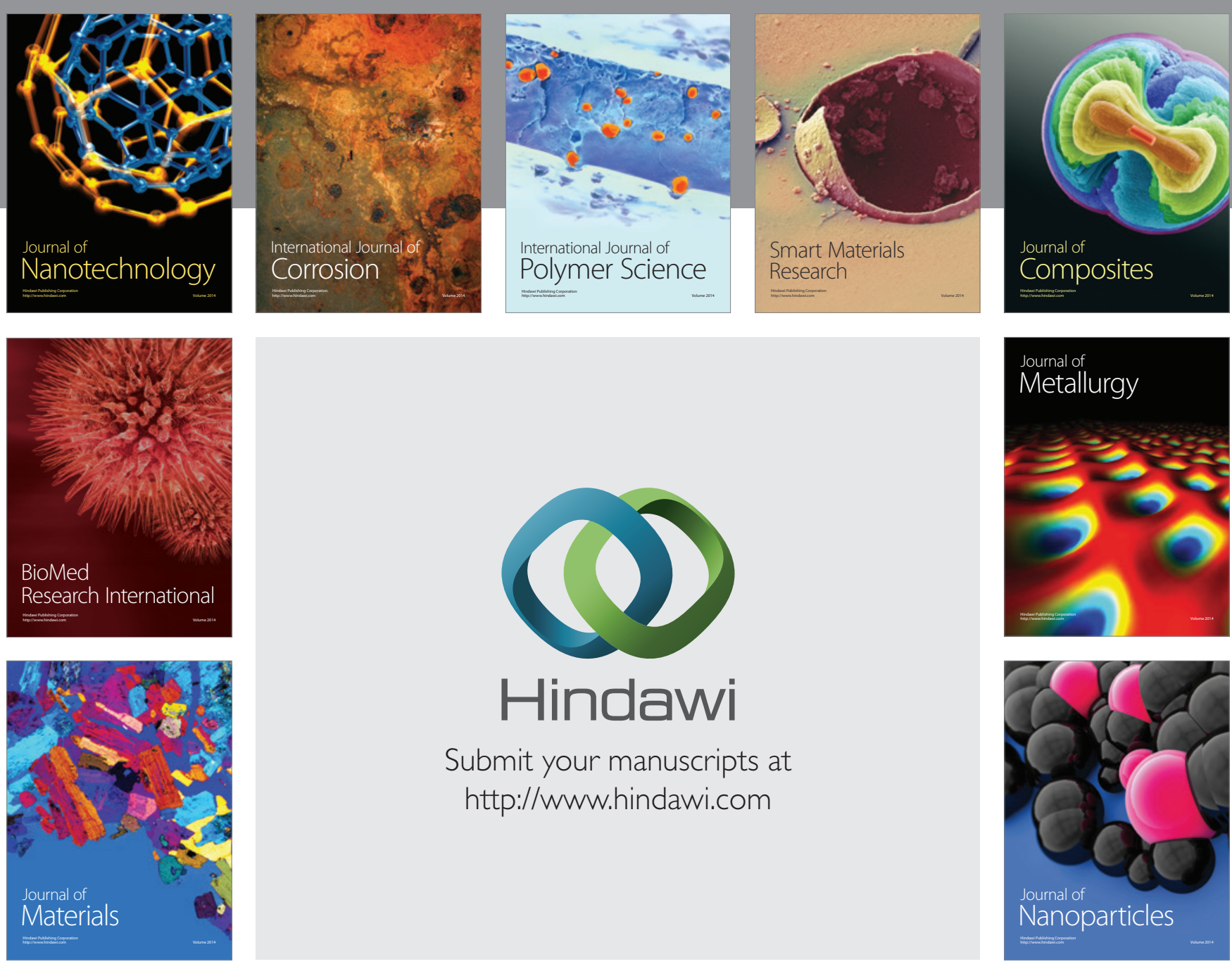

Submit your manuscripts at http://www.hindawi.com
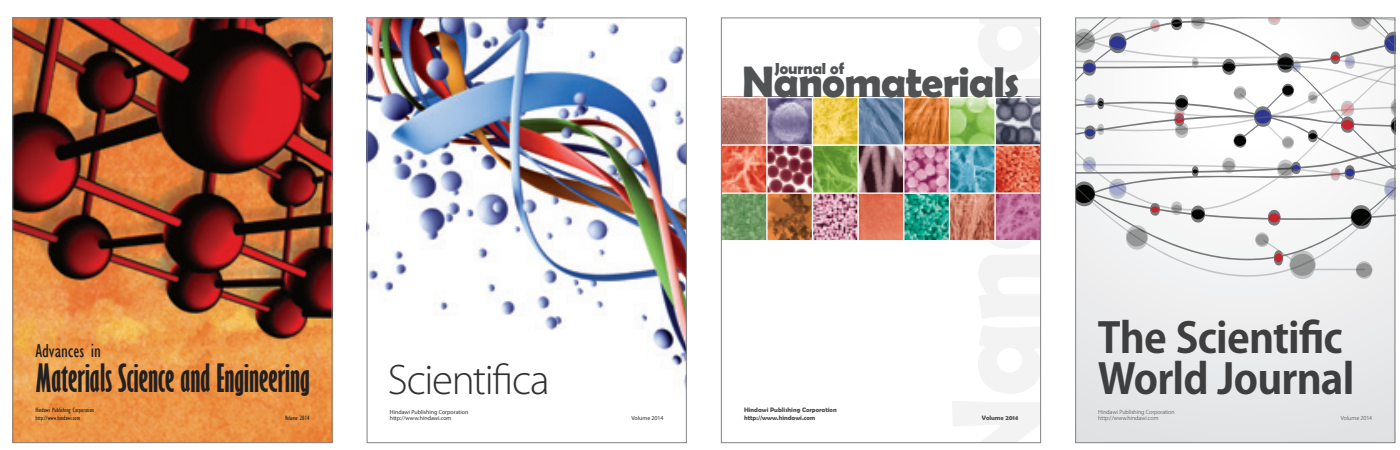

\section{The Scientific World Journal}
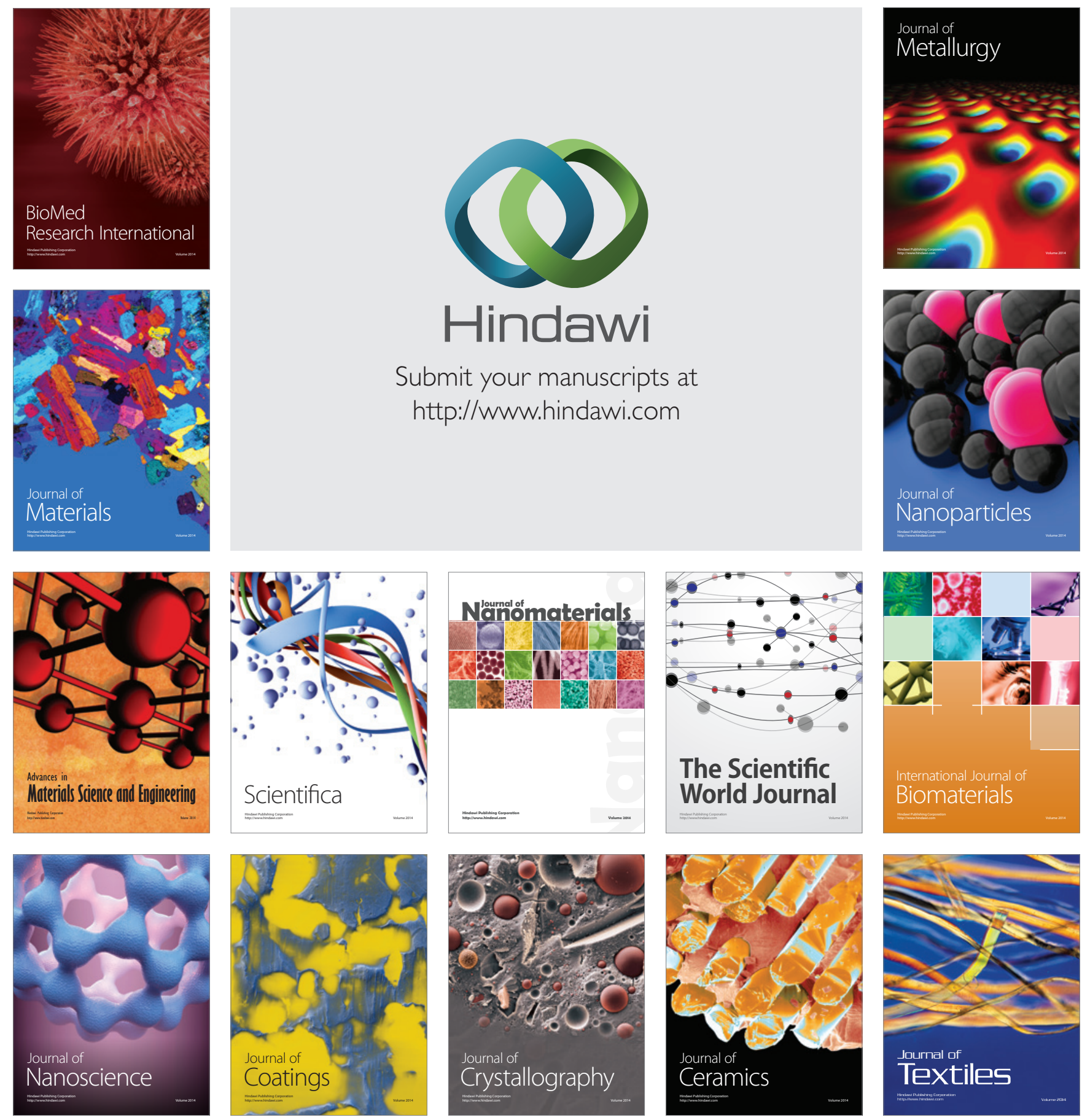